\title{
Climate change and the long-term northward shift in the African wintering range of the barn swallow Hirundo rustica
}

\author{
Roberto Ambrosini ${ }^{1, *}$, Diego Rubolini ${ }^{2}$, Anders Pape Møller ${ }^{3}$, Luciano Bani ${ }^{4}$, \\ Jacquie Clark $^{5}$, Zsolt Karcza ${ }^{6}$, Didier Vangeluwe ${ }^{7}$, Chris du Feu ${ }^{8}$, Fernando Spina ${ }^{9}$, \\ Nicola Saino ${ }^{2}$ \\ ${ }^{1}$ Dipartimento di Biotecnologie e Bioscienze, Università degli Studi di Milano-Bicocca, piazza della Scienza 2, \\ 20126 Milano, Italy \\ ${ }^{2}$ Dipartimento de Biologia, Università degli Studi di Milano, via Celoria 26, 20133 Milano, Italy \\ ${ }^{3}$ Laboratoire d'Ecologie, Systématique et Evolution, CNRS UMR 8079, Université Paris-Sud, Bâtiment 362, 91405 Orsay Cedex, France \\ ${ }^{4}$ Dipartimento di Scienze dell'Ambiente e del Territorio, Università degli Studi di Milano-Bicocca, piazza della Scienza 1, \\ 20126 Milano, Italy \\ ${ }^{5}$ British Trust for Ornithology (BTO), The Nunnery, Thetford, Norfolk IP24 2PU, UK \\ ${ }^{6}$ Madárgyuruzési Központ / Hungarian Bird Ringing Centre - MME / BirdLife Hungary, Költo u. 21, 1121 Budapest, Hungary \\ ${ }^{7}$ Belgian Ringing Centre, Royal Belgian Institute of Natural Sciences, 29 rue Vautier, 1000 Brussels, Belgium \\ ${ }^{8}$ EURING Data bank, BTO, Thetford, Norfolk IP24 2PU, UK \\ ${ }^{9}$ ISPRA, Via Cà Fornacetta 9, 40064 Ozzano dell'Emilia (BO), Italy
}

\begin{abstract}
Recent, unprecedentedly rapid climate change has frequently been invoked as the cause of changes in the phenology of bird migration as well as population decline. Birds would be expected to respond to milder climatic conditions at their breeding grounds by reducing the length of their migration. Here, we exploit the largest ringing recovery database available for a longdistance migrant passerine bird, the barn swallow Hirundo rustica, spanning 1912-2008 and including recoveries from sub-Saharan Africa, to show that this species has shifted its wintering grounds northwards at a rate of 3 to $9 \mathrm{~km} \mathrm{yr}^{-1}$. This shift occurred consistently in the 2 geographical clusters of barn swallows that could be identified on the basis of their migratory connectivity and could bedetected after accounting for possible differential changes in recovery probability among geographical areas. Analyses of trends in climatic conditions at the wintering grounds, based on time series of rainfall and temperature anomalies, showed that this northward shift should have caused a progressively larger proportion of barn swallows to winter in drier or warmer areas, i.e. where primary productivity is lower and therefore ecological conditions for wintering are less favourable. This shift, which may have contributed to the general decline in breeding barn swallow populations, may be due to the combined effects of selection for earlier arrival at the breeding grounds because of milder climatic conditions in the breeding areas, and constraints in other stages of the annual life cycle (e.g. timing of the annual moult) that prevent earlier departure from the wintering grounds.
\end{abstract}

KEY WORDS: Barn swallow · Bird migration · Connectivity · EURING swallow project $\cdot$ Phenology · Wintering range

Resale or republication not permitted without written consent of the publisher

\section{INTRODUCTION}

Climate is a major factor shaping the distribution, abundance and life history of organisms (Begon et al. 2006). The effects of recent, rapid climate change at a global scale have frequently been invoked as the most likely and effective candidate for producing widespread spatial, phenological and demographic changes in species and communities (Parmesan \& Yohe 2003, Parmesan 2006). However, differences in 
fundamental life-history traits among species as well as idiosyncratic micro-evolutionary or phenotypically plastic responses to changes in ecological conditions can generate diversity in the biogeographical and population-level consequences of climate change (Møller et al. 2008, Robinson et al. 2009, Altermatt 2010, Végvári et al. 2010). For example, species that migrate over intercontinental distances are perhaps most likely to undergo changes in their distribution and local abundance because they may experience different patterns of change in ecological conditions (Both et al. 2010, Saino et al. 2011). Indeed, migratory birds have altered their migration and breeding phenology (Crick \& Sparks 1999, Dunn 2004, Lehikoinen et al. 2004, Rubolini et al. 2007), as well as their breeding and winter distribution (Thomas \& Lennon 1999, Valiela \& Bower 2003, Brommer 2004, Fiedler et al. 2004, Huntley et al. 2007, La Sorte \& Thompson 2007, Newton 2008, Visser et al. 2009) in relation to recent climate change. In addition, Barbet-Massin et al. (2009) predicted widespread contractions and shifts in the wintering ranges of Afro-Palearctic migrant passerines in the next century according to climate suitability models applied to future climatic scenarios.

Short- and long-distance migratory birds are expected to differ in their response to climate change (Both et al. 2010, Saino et al. 2011). First, migration behaviour of long-distance migrants is thought to be phenotypically less flexible than that of shortdistance migrants (Pulido \& Widmer 2005). Second, genetic variance in migration behaviour may also be smaller in long- vs. short-distance migrants (Berthold \& Querner 1995, but see Pulido \& Widmer 2005), which may limit any micro-evolutionary response to climate change.

Warmer springs at the breeding grounds should have caused an advancement in arrival from migration and in reproduction, which may be achieved by: (1) faster migration; (2) earlier departure from the wintering grounds; (3) wintering closer to the breeding grounds; (4) a reduction of the time between arrival to the breeding grounds and start of breeding; or (5) (most probably) a mix of these mechanisms (Newton 2008). Bird species that breed and winter in the same hemisphere, such as short-distance migrants, may take advantage from wintering closer to the breeding grounds. Indeed, a warmer climate should both allow for earlier breeding and determine milder conditions at more northern wintering latitudes (Visser et al. 2009). Conversely, the choice of wintering area of birds migrating between hemispheres may be under contrasting selection pressures (Newton 2008). Indeed, bioclimatic regions should shift polewards, and thus distance between optimal breeding and wintering habitats should increase. In any case, if ecological or physiological constraints prevent an earlier or more rapid migration (Coppack \& Both 2002, Rubolini et al. 2005, Coppack et al. 2008), and if selection for breeding earlier is stronger than that for wintering in optimal, but more distant climates, a northward shift in the wintering ranges of long-distance migrants may be expected.

The study of changes in the winter distribution of long-distance migrants and its climatic causes has been hampered by technological constraints on the development of equipment for tracking migration, particularly for small and medium-sized birds. Although this technological gap may be bridged in the near future (e.g. Stutchbury et al. 2009), information from bird ringing will remain the sole, though largely underexploited, source of information on past migration routes and wintering distributions (Fiedler et al. 2004, Newton 2008, Visser et al. 2009, Both et al. 2010).

In the present study of the barn swallow Hirundo rustica, we used the largest ringing recovery data set globally available for any long-distance migratory passerine species to identify possible geographical shifts in the winter distribution during the 20th century. We also addressed several potential sources of bias that may blur the analysis of ring recoveries, e.g. variation in ringing and recovery efforts in different geographical areas. Finally, we examined geographical variation in climatic conditions (rainfall and temperature) in sub-Saharan Africa in order to interpret the causes and consequences of any observed change in winter distribution of barn swallows.

\section{MATERIALS AND METHODS}

\subsection{Data set description}

The entire data set (ALL) included 1042 barn swallows ringed in the European breeding areas (from $36.65^{\circ}$ to $65.42^{\circ} \mathrm{N}$ and from $8.92^{\circ} \mathrm{W}$ to $41.72^{\circ} \mathrm{E}$ ) and recovered in the sub-Saharan wintering range (from $15.20^{\circ} \mathrm{N}$ to $34.80^{\circ} \mathrm{S}$ and from $16.77^{\circ} \mathrm{W}$ to $35.72^{\circ} \mathrm{E}$ ) during 1912-2008 (extracted from The European Union for Bird Ringing [EURING] Data Bank in October 2008). Part of this sample originated from the EURING Swallow Project (Spina 1998). Only individuals that were in the breeding areas during AprilSeptember and in the wintering grounds during October-March (Ambrosini et al. 2009) were included in the data set. Only the northernmost site of 
recovery in the breeding range or the southernmost in the wintering range was considered for the 17 individuals with more than one recovery.

Calendar date of recovery at the wintering grounds was expressed using January 1 (Day 1) as a reference, with dates in October-December expressed as negative numbers (e.g. 30 December $=-1$ ). Individuals recorded during the same winter were assigned to the same year (e.g. 1999 for all individuals recorded between October 1998 and March 1999).

\subsection{Statistical methods}

The analysis of migratory connectivity and the identification of the main clusters into which the population could be divided were performed according to the procedure described in Ambrosini et al. (2009). This analysis resulted in the classification of barn swallows into 2 clusters (see also Ambrosini et al. 2009), one including 495 barn swallows wintering between $15.20^{\circ} \mathrm{N}$ and $12.55^{\circ} \mathrm{S}$ (Cluster North), and the other including 547 individuals wintering between $8.83^{\circ}$ and $34.80^{\circ} \mathrm{S}$ (Cluster South) (Figs. 1B \& 2).

Wintering latitudes and longitudes were regressed on year, cluster, their interaction and the linear and squared terms of date of recovery in the wintering grounds to statistically account for the possibility that recoveries referred to individuals still or already on migration. The Appendix provides further details on statistical methods.

\subsection{Analyses accounting for potential sources of bias}

We evaluated some potential biases due to temporal and spatial variation in sampling effort (Fiedler 2003, Fiedler et al. 2004, Visser et al. 2009). (1) We ran the analyses on individuals that were on the wintering grounds in the period when migratory move-
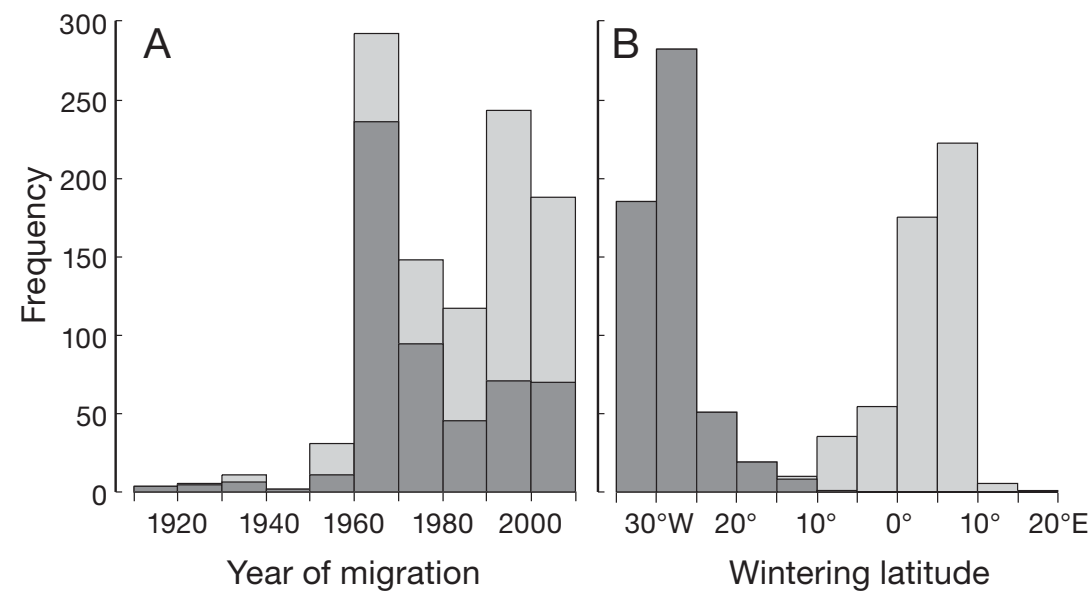

Fig. 1. (A) Temporal and (B) latitudinal distribution of the African winter recoveries of the 495 barn swallows in Cluster North (light grey bars) and the 547 barn swallows of Cluster South (dark grey bars) in the ALL data set

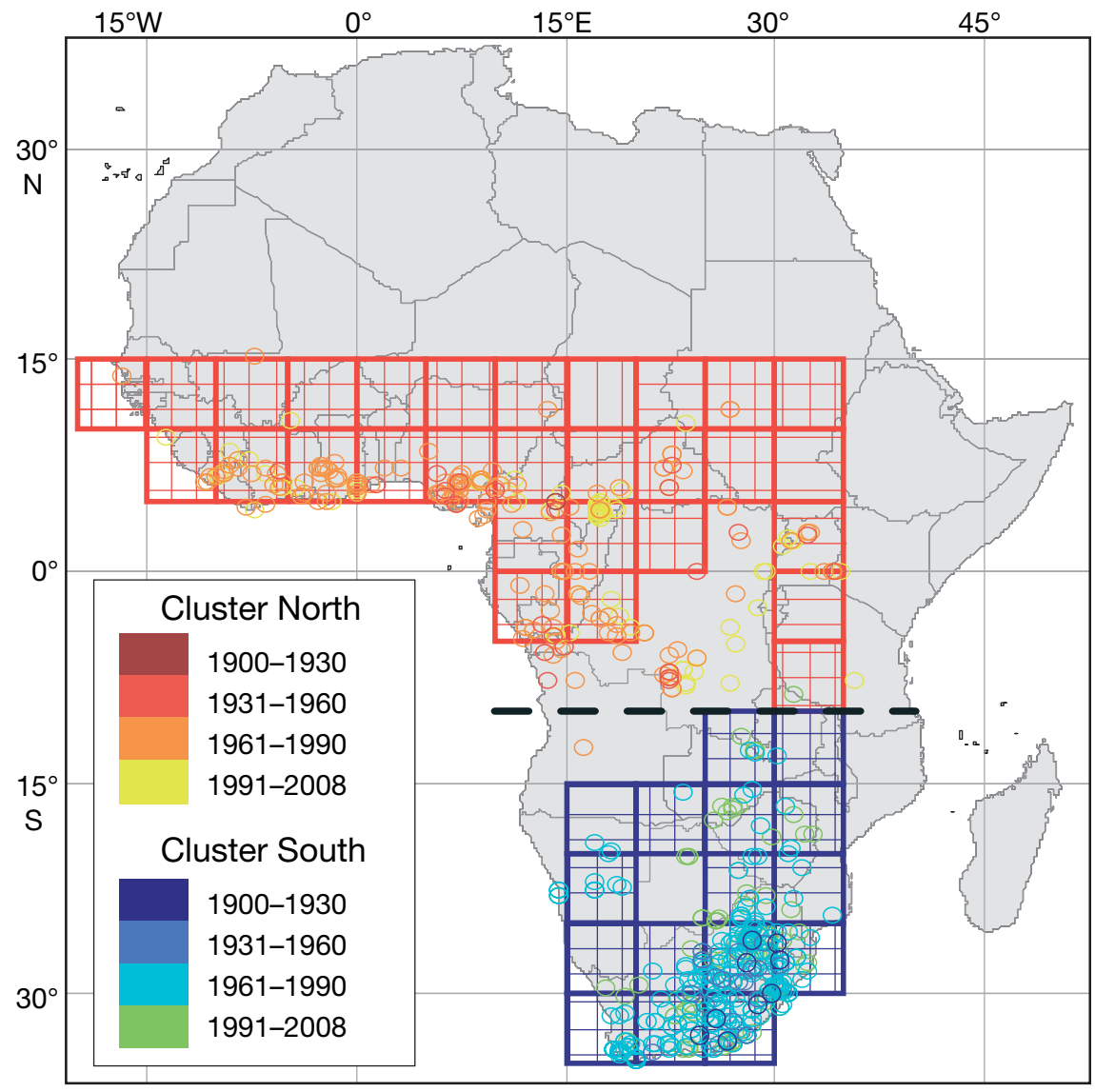

Fig. 2. Wintering position (circles) of the 1042 barn swallows in the ALL data set according to cluster classification (Cluster North $=495$ swallows, Cluster South $=547$ swallows; separated by dashed line) and year of migration (4 classes). Squares represent $5^{\circ}$ latitude $\times 5^{\circ}$ longitude cells used in the analyses of rainfall anomalies (horizontal hatching), temperature anomalies (vertical hatching) or both (cross-hatching) in Cluster North (red) or Cluster South (blue) 
ments can be assumed to be minimal (i.e. DecemberFebruary, 'DF' subset, 595 individuals). We then ran the analyses on individuals that were recorded on the wintering grounds in December-February and were also on the breeding grounds in the focal breeding period (i.e. May-July, 'DF-MJ' subset, 149 individuals).

(2) We accounted for recoveries originating from active trapping by man (e.g. using traps, nets or other catching lures; 274 individuals [46.1\%] in DF, and 70 individuals [47.0\%] in DF-MJ) or from other causes, by including a binary variable ('trapped birds') and its interaction with year in the analyses. This information was retrieved from the field 'circumstances' in the EURING Data Bank. Active trapping corresponded to codes 20-29 in the EURING code (see Speek et al. 2001 for details).

(3) We included a binary variable ('alive') accounting for barn swallows recovered alive (EURING field 'condition', code 7-9, 233 individuals [44.3\%] in DF and 56 individuals [44.4\%] in DF-MJ) or dead (EURING code 'condition' in 1-2, 293 individuals [55.7\%] in DF and 70 [55.6\%] in DF-MJ) and the interaction of this variable with year. If the recovery condition was unknown or not included in those listed above (EURING code 'condition' $=0,3,4,5,6$; Speek et al. 2001), the individuals were excluded from the analysis (69 individuals in DF and 23 in DF-MJ). Consistency of geographical shifts based on either type of recovery data would corroborate the conclusions.

(4) Variation in the ringing and recovery efforts across Europe and Africa may blur the analyses because barn swallow populations breeding in different parts of Europe segregate in the wintering quarters (Ambrosini et al. 2009). We therefore identified geographical populations (clusters, see Section 3.1) with an established connection between the breeding and wintering ranges using migratory connectivity analysis. We incorporated this information in all the analyses by either including a factor 'cluster' and its interaction with year, or running the analyses separately for each cluster.

(5) The analyses on the DF-MJ subset were run including a factor 'European country' to account for variation in trapping efforts among countries and its interaction with year, and by also including 'trapped birds' and 'alive' as factors (this analysis was not run on the ALL and the DF data sets as they may include individuals reported in Europe during migration). In addition, 'African country', accounting for the country where the swallow was recovered, and its interaction with year as well as 'trapped birds' and 'alive' were included in the analysis on the DF data set (the
ALL data set may include swallows recovered in Africa during migration). If the 'African country' $x$ Year interaction was not significant, a shift in the wintering latitude or longitude should not be a byproduct of differential temporal and spatial variation in recovery effort between African countries.

(6) Changes in phenology may result in an apparent shift of the wintering grounds. For example, if birds migrate north earlier, then they may be found at more northerly sites in recent years. We tested whether this effect could potentially bias our results by analyzing temporal variation in the calendar date of recovery in a linear model that included the latitude of recovery as a covariate. This analysis was run separately on the 2 clusters of the DF data set, as the ALL data set may include birds recovered during their southward migration. If migration date has been advancing during the last century, a significant and negative effect of year should emerge, after controlling statistically for the latitude of recovery.

\subsection{Changes in climatic conditions}

Changes in climatic conditions in the wintering range were investigated by analyzing variation in rainfall and temperature in the regions occupied by the 2 clusters separately. Based on the recovery of individuals in the 2 clusters (see Section 2.2 and Figs. 1B \& 2), we considered the region occupied by Cluster North ranging from $15^{\circ} \mathrm{N}$ to $10^{\circ} \mathrm{S}$ and that of Cluster South from $10^{\circ} \mathrm{S}$ to $35^{\circ} \mathrm{S}$, west of $35^{\circ} \mathrm{E}$ in both cases (Fig. 2). We used monthly rainfall and temperature anomalies from the Global Historical Climatology Network of the National Oceanic and Atmospheric Administration (www.ncdc.noaa.gov/ oa/climate/research/ghcn/ghcngrid.html\#data) for a $5^{\circ}$ latitude $\times 5^{\circ}$ longitude grid on land. Only rainfall anomalies during 1921-2008 and temperature anomalies during 1941-2008 were included in the analyses, as very few cells in sub-Saharan Africa had anomaly data outside those periods. Within these temporal ranges, we selected grid cells with time series for rainfall or temperature anomalies ending at least in year 2000 (although to account for climate change in recent years, when a large number of barn swallows was recovered, we included in the analyses all years until 2008 for all grid cells for which these data were available; Fig. 1A). This selection resulted in 44 grid cells (28 in Cluster North and 16 in Cluster South) for rainfall anomalies and 38 grid cells (24 in Cluster North and 14 in Cluster South) for temperature anomalies (Fig. 2). 
Mean rainfall and temperature anomalies for the whole year before each spring migration (from April of year $i-1$ to March of year $i$, where $i$ is the winter season of barn swallows, see above) or for the focal wintering period (December of year i-1 to February of year $i$ ) were calculated for each cell. The analysis of mean April-March anomalies investigates changes in general climatic conditions affecting, for example, primary productivity during the whole year, whereas that run on mean December-February anomalies may account for among-year changes in environmen-

Table 1. Linear regression models of wintering latitude of barn swallows based on 3 data sets with all non-significant factors removed. ALL: entire data set; DF: December-February subset; DF-MJ: December-February and May-July subset

\begin{tabular}{|c|c|c|c|c|}
\hline Effect & Coefficient & $\mathrm{SE}$ & $t$ & $\mathrm{p}$ \\
\hline \multicolumn{5}{|c|}{ ALL (1042 individuals) } \\
\hline Intercept & -63.921 & 26.145 & -2.445 & 0.015 \\
\hline Year & 0.034 & 0.013 & 2.579 & 0.010 \\
\hline Cluster & -122.879 & 33.984 & -3.616 & $<0.001$ \\
\hline Date of recovery & -0.011 & 0.003 & -3.456 & $<0.001$ \\
\hline \multirow[t]{2}{*}{ Cluster $\times$ Year } & 0.046 & 0.017 & 2.706 & 0.007 \\
\hline & \multicolumn{4}{|c|}{$F_{4,1037}=3664, \mathrm{p}<0.001$} \\
\hline \multicolumn{5}{|c|}{ DF (595 individuals) } \\
\hline Intercept & -165.437 & 22.934 & -7.214 & $<0.001$ \\
\hline Year & 0.085 & 0.012 & 7.382 & $<0.001$ \\
\hline \multirow[t]{2}{*}{ Cluster } & -31.349 & 0.404 & -77.602 & $<0.001$ \\
\hline & \multicolumn{4}{|c|}{$F_{2,592}=3758, \mathrm{p}<0.001$} \\
\hline \multicolumn{5}{|c|}{ DF-MJ (149 individuals) } \\
\hline Intercept & -129.356 & 40.331 & -3.207 & 0.002 \\
\hline Year & 0.067 & 0.020 & 3.288 & 0.001 \\
\hline \multirow[t]{2}{*}{ Cluster } & -30.434 & 0.855 & -35.601 & $<0.001$ \\
\hline & \multicolumn{4}{|c|}{$F_{2,146}=719.8, \mathrm{p}<0.001$} \\
\hline
\end{tabular}

tal conditions experienced by barn swallows during winter in a given year.

In order to describe variation in temporal trends of rainfall and temperature anomalies at different latitudes, we regressed anomalies in each cell on latitude (included as a fixed factor), year and their interaction using generalized least squares models that also accounted for temporal autocorrelation in the data from the same cell. The description of the temporal trends at each $5^{\circ}$-wide latitudinal belt was obtained by regressing anomalies in the cells of a given belt on year while accounting for within-cell temporal autocorrelation. These analyses were run with the gls function in the nlme library (Pinheiro et al. 2008) in R 2.8.1 (R Development Core Team 2008). Temporal trends of rainfall and temperature anomalies at different longitudes were not investigated, as no consistent evidence of a longitudinal shift in the wintering range was detected (see Section 3).

\section{RESULTS}

\subsection{Migratory connectivity and wintering range shift}

Individuals in the ALL data set showed significant migratory connectivity $\left(\mathrm{r}_{\mathrm{M}}=0.234, \mathrm{p}<0.001\right)$, with 2 main clusters (overall average silhouette width = 0.649; Cluster North: 495 swallows; Cluster South: 547 swallows; Fig. 2).

Wintering latitude shifted northwards during the last century, and more so for individuals of Cluster South than for those of Cluster North of the ALL data set (Table 1, Fig. 3A). Indeed, individuals of Cluster North shifted northwards by $\sim 3.45 \pm 1.44 \mathrm{~km} \mathrm{yr}^{-1}$
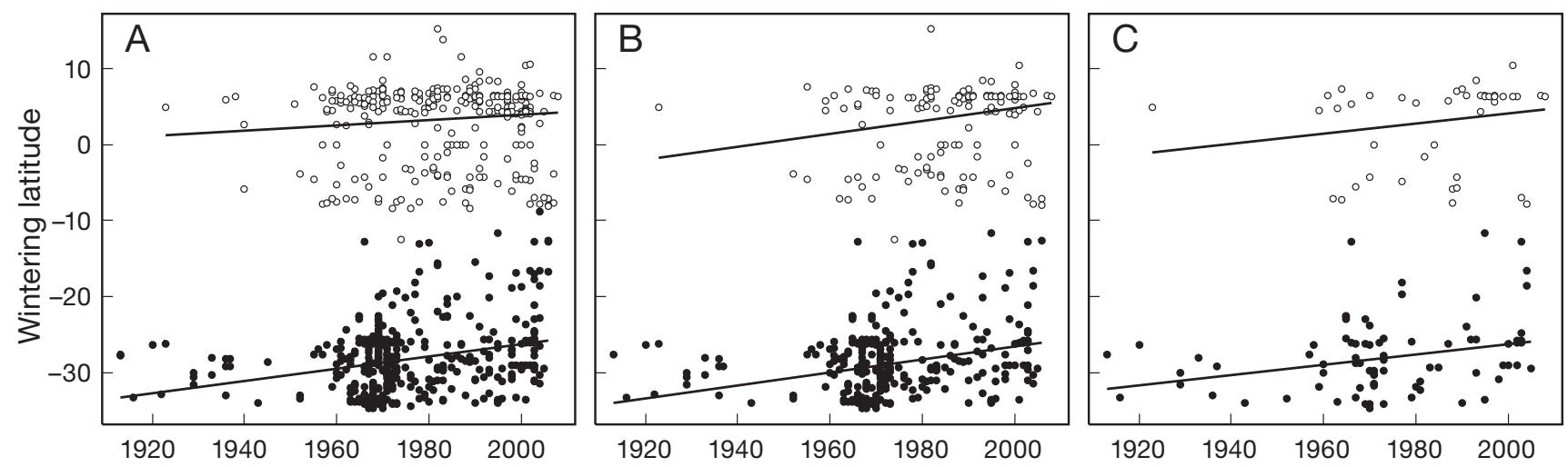

Fig. 3. Variation in wintering latitude of (A) the 1042 individual barn swallows of the ALL data set, (B) the 595 individuals of the DF (December-February) data set and (C) the 149 individuals in the DF-MJ (December-February and May-July) data set during the last century. Open symbols refer to Cluster North, filled symbols to Cluster South (see Fig. 2). Regression lines are drawn according to parameters from final regression models (Table 1) 
(mean $\pm \mathrm{SE}$ ), whereas those of Cluster South shifted by $8.89 \pm 1.22 \mathrm{~km} \mathrm{yr}^{-1}$ (these estimates were obtained form the coefficients in Table 1 assuming $1^{\circ}$ latitude $=$ $111.14 \mathrm{~km})$. The effect of the linear term of date was significant and negative, indicating that individuals were recorded mostly during southward migration.

Analyses on DF and DF-MJ subsets confirmed the northward shift in wintering latitude during the last century. The Cluster $\times$ Year interaction was not significant, thus indicating that the northward shift did not differ between clusters of individuals (Table 1, Fig. 3B,C). The non-significant effect of date (removed from the final model) suggests that the position of individuals was recorded in their final wintering grounds. The coefficients from the model indicate a northward shift of $9.45 \pm 1.33 \mathrm{~km} \mathrm{yr}^{-1}$ in DF and $7.45 \pm$ $2.22 \mathrm{~km} \mathrm{yr}^{-1}$ in DF-MJ.

Analyses of wintering latitudes re-run on each data set while including the factor 'trapped birds' confirmed the significant shift in wintering latitudes $\left(|t|_{144} \geq 3.228, \mathrm{p} \leq 0.001\right)$. In addition, both the factor 'trapped birds' and its interaction with year and cluster were never significant $\left(|t|_{588} \leq 1.46, \mathrm{p} \geq 0.15\right)$, implying that the shift in wintering grounds was independent of the circumstances under which a bird was recovered, and occurred at a similar temporal rate. The 'alive' $\times$ Year interaction was found to be significant in the analysis run on the DF subset $\left(t_{521}=2.610\right.$, $\mathrm{p}=0.009$ ), thus implying that a differential temporal shift was apparent in barn swallows found dead or alive. However, the coefficients of the models revealed that a significant northward shift could be detected based both on recoveries of dead swallows $\left(0.06 \pm 0.02^{\circ} \mathrm{yr}^{-1}, t_{521}=3.767, \mathrm{p}<0.001\right.$, corresponding to $\sim 6.67 \pm 2.22 \mathrm{~km} \mathrm{yr}^{-1}$ ) and on barn swallows recaptured alive $\left(0.12 \pm 0.02^{\circ} \mathrm{yr}^{-1}, t_{521}=6.851, \mathrm{p}<\right.$ 0.001 , corresponding to $\sim 13.34 \pm 2.22 \mathrm{~km} \mathrm{yr}^{-1}$ ). The interaction term was not significant $\left(t_{121}=0.474, \mathrm{p}=\right.$ 0.636) in the same analysis run on the DF-MJ, nor was the main effect of factor 'alive' $\left(t_{122}=0.981, \mathrm{p}=\right.$ $0.329)$, so the interaction term was removed.

The 'European country' $\times$ Year interaction was not significant in a model run on the DF-MJ subset, and it was still not significant when factor 'trapped birds' or 'alive' was included in the analyses $\left(F_{14,115} \leq 1.53\right.$, $\mathrm{p} \geq 0.11$ ). When we removed the non-significant interactions, a significant increase in wintering latitude was detected in all models $\left(|t|_{129} \geq 2.131, \mathrm{p} \leq 0.035\right)$. Similarly, the African country $\times$ Year interaction was not significant in an analysis run on the DF subset, nor was it significant in the analyses including factors 'trapped birds' and 'alive' $\left(F_{19,489} \leq 1.302, \mathrm{p} \geq 0.196\right)$. Also in this case, a significant northward shift was detected in all models, after removing non-significant interactions $\left(|t|_{572} \geq 2.344, \mathrm{p} \leq 0.019\right)$.

After controlling for latitude, the effect of which was non-significant in both models $\left(|t|_{382} \leq 1.38, \mathrm{p} \geq\right.$ $0.167)$, calendar date of recovery of birds of Cluster North did not change significantly with year (coefficient $=0.047 \pm 0.149 \mathrm{~d} \mathrm{yr}^{-1}, \mathrm{n}=210, t_{207}=0.313, \mathrm{p}=$ 0.755), whereas that of birds of Cluster South significantly increased with year (coefficient $=0.172 \pm$ $0.084 \mathrm{~d} \mathrm{yr}^{-1}, \mathrm{n}=385, t_{382}=2.055, \mathrm{p}=0.041$ ), thus suggesting that individuals of this cluster have migrated north later, rather than earlier, in recent years.

Analysis of wintering longitude run on the ALL data set indicated that the wintering range of both clusters shifted eastwards during the last century (Cluster North: coefficient $=0.118 \pm 0.028^{\circ} \mathrm{yr}^{-1}, t_{1036}=4.208$, $\mathrm{p}<0.001$; Cluster South: coefficient $=0.023 \pm 0.010^{\circ}$ $\mathrm{yr}^{-1}, t_{1036}=2.302, \mathrm{p}=0.002$ ). However, the same analyses run on the DF and DF-MJ subsets did not confirm the shift in wintering longitudes (DF: coefficient = $0.019 \pm 0.011^{\circ} \mathrm{yr}^{-1}, t_{592}=1.683, \mathrm{p}=0.093 ; \mathrm{DF}-\mathrm{MJ}$ : $\mathrm{co}-$ efficient $=0.021 \pm 0.019^{\circ} \mathrm{yr}^{-1}, t_{146}=1.088, \mathrm{p}=0.278$, other details not shown). Thus, evidence for a longitudinal shift of wintering ranges was inconsistent.

\subsection{Rainfall and temperature trends}

Latitudinal variation in temporal trends of rainfall anomalies was obvious only for the wintering area of Cluster North (Table 2). Annual rainfall declined north of $5^{\circ} \mathrm{N}$ whereas no significant change occurred in the area between $5^{\circ} \mathrm{N}$ and $10^{\circ} \mathrm{S}$. During the wintering period of the barn swallow, rainfall decreased only between $0^{\circ}$ and $10^{\circ} \mathrm{N}$, and showed no significant changes elsewhere in Cluster North. In the wintering area of Cluster South, there has been no apparent change in rainfall (Table 2).

A significant latitudinal variation in temporal trends of temperature anomalies was observed in the wintering range of Cluster North (Table 2), where mean annual temperature increased significantly in the northernmost area of the cluster. Temperature anomalies in December-February increased significantly from $5^{\circ}$ to $10^{\circ} \mathrm{S}$ and from $10^{\circ}$ to $15^{\circ} \mathrm{N}$, and decreased in the area between $0^{\circ}$ and $5^{\circ} \mathrm{N}$, showing no significant variation elsewhere. No significant latitudinal variation in the temporal trends of temperature was found in the area of Cluster South, where temperature globally rose, as indicated by the positive signs of all coefficients (Table 2), the only exception being a non-significant increase in mean annual temperature from latitudes $30^{\circ}$ to $35^{\circ} \mathrm{S}$. 
Table 2. Rainfall and temperature trends in 5 latitudinal $5^{\circ}$-wide belts in the African wintering grounds of Cluster North $\left(15^{\circ} \mathrm{N}-10^{\circ} \mathrm{S}\right)$ and Cluster South $\left(10^{\circ}-35^{\circ} \mathrm{S}\right)$ west of longitude $35^{\circ} \mathrm{E}$. Data for the entire years (April-March) and the core wintering periods (December-February) were used. Values are slopes (SE) obtained from generalized least squares (GLS) models with a first-order autoregressive covariance structure of rainfall $(\mathrm{mm} \times 100)$ or temperature $\left({ }^{\circ} \mathrm{C} \times 100\right)$ in relation to year (covariate; range for rainfalls: 1921-2008; range for temperatures: 1941-2008) for each latitudinal belt. Area (5latitude $\times 5^{\circ}$ longitude) within latitudinal belt was included as a grouping (subject) factor. The Latitude $\times$ Year interaction effects are calculated from different GLS models for rainfall or temperature anomalies where latitude was entered as a 5-level factor. Statistical significance: ${ }^{*} \mathrm{p}<0.05{ }_{i}{ }^{* *} \mathrm{p}<0.01 ;{ }^{* * *} \mathrm{p}<0.001$

\begin{tabular}{|c|c|c|c|c|}
\hline & \multicolumn{2}{|c|}{-Rainfall } & \multicolumn{2}{|c|}{ - Temperature } \\
\hline & April-March & December-February & April-March & December-February \\
\hline \multicolumn{5}{|l|}{ Cluster North } \\
\hline $10^{\circ}-15^{\circ} \mathrm{N}$ & $-17.35(1.69)$ & $-0.33(0.18)$ & $1.084(0.137)^{* * *}$ & $0.881(0.183)^{* * *}$ \\
\hline $5^{\circ}-10^{\circ} \mathrm{N}$ & $-19.09(3.07)^{* * *}$ & $-5.53(1.24)^{* * *}$ & $-0.172(0.192)$ & $-0.286(0.222)$ \\
\hline $0^{\circ}-5^{\circ} \mathrm{N}$ & $5.72(3.92)$ & $-12.00(4.29)^{* *}$ & $-0.584(0.373)$ & $-0.868(0.355)^{*}$ \\
\hline $0^{\circ}-5^{\circ} \mathrm{S}$ & $1.44(5.03)$ & $11.10(8.25)$ & $0.235(0.289)$ & $0.002(0.253)$ \\
\hline $5^{\circ}-10^{\circ} \mathrm{S}$ & $1.30(5.52)$ & $27.30(14.51)$ & $1.462(0.331)$ & $1.116(0.364)^{* *}$ \\
\hline \multirow[t]{2}{*}{ Latitude $\times$ Year } & $F_{4,2358}=11.973$ & $F_{4,2321}=11.611$ & $F_{4,1503}=11.030$ & $F_{4,1462}=7.800$ \\
\hline & $\mathrm{p}<0.001$ & $\mathrm{p}<0.001$ & $\mathrm{p}<0.001$ & $\mathrm{p}<0.001$ \\
\hline \multicolumn{5}{|l|}{ Cluster South } \\
\hline $10^{\circ}-15^{\circ} \mathrm{S}$ & 5.35 (3.96) & 4.57 (8.83) & $1.749(0.603)^{* *}$ & $0.201(0.445)$ \\
\hline $15^{\circ}-20^{\circ} \mathrm{S}$ & $-4.02(2.98)$ & $-4.16(9.72)$ & $1.691(0.722)^{*}$ & $1.239(0.411)^{* *}$ \\
\hline $20^{\circ}-25^{\circ} \mathrm{S}$ & $-2.17(3.34)$ & $0.23(9.05)$ & $2.087(0.773)^{* *}$ & $1.792(0.613)^{* *}$ \\
\hline $25^{\circ}-30^{\circ} \mathrm{S}$ & $-0.11(2.20)$ & $5.93(5.64)$ & $1.118(0.211)^{* * *}$ & $1.071(0.237)^{* * *}$ \\
\hline $30^{\circ}-35^{\circ} \mathrm{S}$ & $-0.48(1.81)$ & $4.92(3.40)$ & $0.492(0.427)$ & $0.717(0.321)^{*}$ \\
\hline \multirow[t]{2}{*}{ Latitude $\times$ Year } & $F_{4,1354}=1.267$ & $F_{4,1340}=0.348$ & $F_{4,894}=1.619$ & $F_{4,882}=1.873$ \\
\hline & $\mathrm{p}=0.243$ & $\mathrm{p}=0.846$ & $\mathrm{p}=0.167$ & $\mathrm{p}=0.113$ \\
\hline
\end{tabular}

\section{DISCUSSION}

In this study we investigated whether the African wintering ranges of the barn swallow have changed between 1912 and 2008 using the distribution of recoveries of ringed birds, and whether any observable geographical shift can be attributed to longterm climate change. These analyses were based on the largest data set of ringing recoveries available for any long-distance migratory passerine bird species.

European barn swallows showed strong migratory connectivity and could be assigned to 2 clusters that segregated their wintering grounds approximately at $10^{\circ} \mathrm{S}$. These clusters represent distinct groups of individuals identified based on their reciprocal positions both in the breeding and the wintering quarters (Ambrosini et al. 2009) (see Appendix). These findings are consistent with a previous study (Ambrosini et al. 2009) based on a partly different data set (data in that study were restricted to recoveries from the EURING national member schemes up to 1998 and included those of birds marked by The South African Bird Ringing Unit [SAFRING], which are not included in the present work as they are not hosted within the EURING Data Bank).
Barn swallow populations have shifted their wintering ranges northwards by 350 to $950 \mathrm{~km}$ during the last century, depending on the specific subset of data, whereas no consistent evidence of a longitudinal shift was found. In the set including all available recoveries (ALL), a significant difference in the rate of geographical shift between the 2 main clusters was also apparent. Indeed, Cluster South shifted its wintering range northwards 2 to 3 times more than Cluster North, whereas Cluster North shifted eastwards 4 to 5 times more than Cluster South. The latitudinal shift was consistent in analyses run on different subsets of data, and when including variables accounting for possible sampling bias. In particular, we accounted for possible biases arising from: (1) birds recovered during migration, (2) recovery conditions of individuals, (3) the European country where swallows were ringed, partly accounting for differential temporal variation in ringing effort in different parts of Europe, and (4) the African country where swallows were recovered, partly accounting for differential temporal variation in recovery effort in different sectors of the wintering grounds. In addition, the analysis that included a factor accounting for individuals being recovered dead or alive revealed that the 
latitudinal shift in the wintering distribution based on recoveries of live barn swallows was larger than that estimated from recoveries of dead individuals alone. However, caution is needed in the interpretation of this result, as it was not confirmed in the analysis on the DF-MJ subset. The larger shift in recoveries of live compared with dead birds suggests that the shift in wintering range we observed is not the byproduct of an increasing recovery probability of dead ringed birds in the Northern part of the wintering areas.

Temporal changes in the phenology of migration should also not have blurred our results, as the analyses of temporal change in the date of recovery showed no significant variation for the individuals of Cluster North, and a significant delay for those of Cluster South. If birds have advanced departure from their wintering grounds, and thus an increased probability of being found at more northerly sites earlier in the season in recent years, an advance, rather than a delay, in the date of recovery at any given latitude should be expected. The evidence of a northward shift in the winter range of Cluster North is therefore unaffected by this potential confounding effect. However, the shift of Cluster South was detected despite a delay in migration phenology, and the actual shift is thus likely to be larger than the estimated one. In addition, the distribution of barn swallows has been recorded in the Southern African bird atlases during 1987-1993 (Harrison et al. 1997) and again from 2008 onwards. Barn swallows have shown a significant northward distributional shift in winter between these 2 projects (P. Barnard pers. comm.).

The northward shift in the wintering range could be observed in all the analyses accounting for potential sources of bias. We therefore regard the possibility that the present results were due to changes over time in the spatial distribution of the chances of recovery of ringed barn swallows as an unlikely one. However, the recovery probability could not be estimated explicitly, and therefore we could not account for its temporal and spatial variation, if any. Modelling recovery probabilities was impractical on data collected over an area as large as the African continent over a century, as no direct information on recovery effort is available for several regions and periods in Africa. In addition, information on proxies of the recovery effort (e.g. population density; Wernham \& Siriwardena 2002), are fragmentary or available only at very coarse scales.

Shortening of bird migration routes has already been demonstrated for geographical populations of (mainly) short-distance migrants (Siriwardena \& Wernham 2002, Fiedler et al. 2004, La Sorte \&
Thompson 2007, Visser et al. 2009, Pulido \& Berthold 2010). To our knowledge, the present study represents the first evidence of a general northward shift in the wintering range of a long-distance migrant which breeds and winters on different continents.

Rainfall has decreased during the last century in the northern part of the wintering area of Cluster North (Table 2; see also Hulme et al. 2001, Giannini et al. 2008, Newton 2008), whereas in the wintering area of Cluster South temperatures have generally increased. The northward shift in wintering grounds of either cluster thus implies that an increasing proportion of barn swallows is now wintering in areas that have become progressively drier or warmer during the last century. High rainfall in the wintering grounds enhanced winter survival (Szép et al. 2006) and phenotypic quality (Saino et al. 2004) of barn swallows, possibly via an effect on primary productivity and thus food availability (Szép et al. 2006). The northward shift in wintering ranges thus seems to have brought barn swallows to areas where ecological conditions for wintering have progressively deteriorated. This may be particularly true for barn swallows of Cluster North, with decreased rainfall in the northern part of the wintering range. This may also be one of the causes for the smaller northward shift of this cluster compared with Cluster South. Constraints in the northward shift may indeed be less stringent for barn swallows of Cluster South, as their wintering range is not bordered by a large, inhospitable area such as the Sahara Desert to the north. In addition, ecological conditions in the area of Cluster North may also affect barn swallows of Cluster South, as the latter cross the wintering area of Cluster North during migration.

Climate suitability models applied to future climate scenarios predict that African wintering ranges of migratory passerines will shift southwards in this century (Barbet-Massin et al. 2009). This implies that the northern part of the actual wintering range of a species will become inhospitable for that species. According to these models, species wintering in the Southern Hemisphere should shift their wintering range polewards, according to the predicted shift of biomes under a warming climate (IPCC 2007). However, species wintering in the Northern Hemisphere in sub-Saharan Africa should also shift southwards, as the desert is predicted to expand in the future (IPCC 2007). As a consequence of the Sahara desert expansion, climate suitability models also predict an eastward shift in the ranges of species wintering in western Africa (Barbet-Massin et al. 2009), which is consistent with the longitudinal shift of Cluster North 
observed in the ALL data set. Unfortunately, the number of individuals recovered in each year is too small to allow an analysis of wintering latitude or longitude in relation to climatic conditions in individual years, which would be required for an analysis directly assessing the causal effect of climatic conditions on wintering positions. Hence, even the data set of barn swallow ringing recoveries, which is the largest available for any long-distance migratory passerine bird, would not be sufficient for a direct test of the effect of climate on wintering position.

The northward shift in wintering grounds may be the result of a selection pressure towards earlier arrival dates combined with constraints and/or selection acting in other stages of the annual life cycle of barn swallows that may prevent an earlier departure from the wintering grounds, a faster migration and/ or a reduced time between arrival and breeding. General predictions about the response of migratory birds to climate change envisage that migrants should respond to milder climatic conditions at northern latitudes by arriving to the breeding grounds earlier (Newton 2008, Visser et al. 2009, Lehikoinen \& Sparks 2010). Temperatures in Europe increased by $0.9^{\circ} \mathrm{C}$ during the last century (Jones \& Moberg 2003, Parry et al. 2007), and, consistent with predictions, barn swallows have advanced their arrival on the breeding grounds in $80 \%$ of the European long-term time series of arrival dates (Lehikoinen et al. 2004). Constraints on the onset of spring migration (Coppack \& Both 2002) may explain the observed northward shift in wintering grounds, which apparently brought swallows toward areas where ecological conditions have worsened. For example, birds may be unable to leave their wintering grounds before the annual moult of flight feathers has been completed (e.g. Rubolini et al. 2005, Møller et al. 2011). If the timing of the annual moult, or any other constraint affecting departure date, can only be adjusted with difficulty, and if fitness payoffs of early arrival to the breeding grounds in time to exploit peak food resources for reproduction are high, then an optimal strategy for choosing a wintering area would be to winter in the most profitable place allowing for an early arrival to the breeding grounds in order to achieve higher breeding success. Interestingly, Coppack et al. (2008), in a study on the photoperiodic regulation of the termination of prenuptial moult and the initiation of spring migratory activity and gonadal growth in the pied flycatcher Ficedula hypoleuca, have recently demonstrated that birds may be unable to tune the timing of critical stages of the annual life cycle while wintering beyond a critical latitude.
The shift in the wintering grounds may have potential implications for the demography of this declining species. Indeed, sub-optimal northern wintering habitats may sustain only a fraction of the wintering population of barn swallows because of reduced carrying capacity. These individuals may obtain a fitness gain from their early arrival to the breeding grounds. However, despite having wintered in more hospitable areas, other individuals may be at a selective disadvantage as they may arrive later thus being unable to match changes in spring phenology on the breeding grounds. Coupled with environmental changes taking place on the breeding grounds, this mechanism may contribute to the observed decline in numbers in several barn swallow populations as well as in other migrants (Møller 1989, Tucker \& Heath 1994, PECBMS 2009).

Acknowledgements. This paper originates from decades of field efforts by thousands of ringers all across Europe and by all those who reported ringed swallows from the vast African winter quarters of a species which is one of the symbols of migration. We warmly thank all these people. A special thank you goes to all ringers who intensified their efforts during the EURING Swallow Project. Recoveries have been coded, processed and collated within the EURING Data Bank by National Ringing Centres from: Belgium, the Channel Islands, the Czech Republic, Denmark, the Federal Republic of Yugoslavia, Finland, France, Germany (Radolfzell, Helgoland, Hiddensee), Greece, Hungary, Italy, Latvia, Lithuania, Norway, Poland, Portugal, Russia, Spain (Madrid, San Sebastian), Sweden, Switzerland, The Netherlands, Turkey, Ukraine and the UK. We express our gratitude to the EURING community of National Ringing Centres and to all the many colleagues for contributing to such a large sample of long-distance recoveries for a passerine migrant.

\section{LITERATURE CITED}

Altermatt F (2010) Tell me what you eat and I'll tell you when you fly: diet can predict phenological changes in response to climate change. Ecol Lett 13:1475-1484

Ambrosini R, Møller AP, Saino N (2009) A quantitative measure of migratory connectivity. J Theor Biol 257:203-211

Barbet-Massin M, Walther BA, Thuiller W, Rahbek C, Jiguet F (2009) Potential impacts of climate change on the winter distribution of Afro-Palaearctic migrant passerines. Biol Lett 5:248-251

Begon M, Townsend C, Harper J (2006) Ecology: from individuals to ecosystems, 4th edn. Blackwell, Oxford

Berthold P, Querner U (1995) Microevolutionary aspects of bird migration based on experimental results. Isr J Zool 41:377-385

Both C, Van Turnhout CAM, Bijlsma RG, Siepel H, Van Strien AJ, Foppen RPB (2010) Avian population consequences of climate change are most severe for long-distance migrants in seasonal habitats. Proc Biol Sci 277: 1259-1266

Brommer JE (2004) The range margins of northern birds shift polewards. Ann Zool Fenn 41:391-397 
Coppack T, Both C (2002) Predicting life-cycle adaptation of migratory birds to global climate change. In: Both $\mathrm{C}$, Piersma T (eds) The avian calendar: exploring biological hurdles in annual cycle. Proc 3rd Conf Europ Ornithol Union, Groningen, p 369-378

Coppack T, Tindemans I, Czisch M, Van der Linden $A_{1}$ Berthold P, Pulido F (2008) Can long-distance migratory birds adjust to the advancement of spring by shortening migration distance? The response of the pied flycatcher to latitudinal photoperiodic variation. Glob Change Biol 14:2516-2522

Crick HQP, Sparks TH (1999) Climate change related to egg-laying trends. Nature 399:423

Dunn PO (2004) Breeding dates and reproductive performance. Adv Ecol Res 35:67-85

Fiedler W (2003) Recent changes in migratory behaviour of birds: a compilation of field observations and ringing data. In: Bertholds P, Gwinner E, Sonnenschein E (eds) Avian migration. Springer, Berlin, p 21-38

Fiedler W, Bairlain F, Köppen U (2004) Using large-scale data from ringed birds for the investigation of effects of climate change on migrating birds: pitfall and prospects. In: Møller AP, Fiedler W, Berthold P (eds) Birds and climate change. Academic Press, London, p 49-67

> Giannini A, Biasutti M, Held IM, Sobel AH (2008) A global perspective on African climate. Clim Change 90:359-383

Harrison JA, Allan DG, Underhill LG, Herremans M, Tree AJ, Parker V, Brown CJ (1997) The Atlas of Southern African birds. BirdLife South Africa, Johannesburg

- Hulme M, Doherty R, Ngara T, New M, Lister D (2001) African climate change: 1900-2100. Clim Res 17:145-168

Huntley B, Green RE, Collingham YC, Willis SG (2007) A climatic atlas of European breeding birds. Durham University, RSPB, and Lynx Edicions, Barcelona

IPCC (2007) Climate change 2007: the physical science basis. Contribution of Working Group I to the Fourth Assessment Report of the Intergovernmental Panel on Climate Change. Cambridge University Press, Cambridge

> Jones PD, Moberg A (2003) Hemispheric and large-scale surface air temperature variations: an extensive revision and an update to 2001. J Clim 16:206-223

La Sorte FA, Thompson FR III (2007) Poleward shifts in winter ranges of North American birds. Ecology 88: 1803-1812

Lehikoinen E, Sparks TH (2010) Changes in migration. In: Møller AP, Fiedler W, Berthold P (eds) Effects of climate change on birds. Oxford University Press, Oxford

Lehikoinen E, Sparks TH, Zalakevicius M (2004) Arrival and departure dates. In: Møller AP, Fiedler W, Berthold P (eds) Birds and climate change. Academic Press, London, p 1-31

Møller AP (1989) Population dynamics of a declining swallow Hirundo rustica L. population. J Anim Ecol 58: 1051-1063

Møller AP, Nuttal R, Piper SE, Szép T, Vickers EJ (2011) Migration, moult and climate change in barn swallow Hirundo rustica in South Africa. Clim Res 47:201-205

> Møller AP, Rubolini D, Lehikoinen E (2008) Populations of migratory bird species that did not show a phenological response to climate change are declining. Proc Natl Acad Sci USA 105:16195-16200

Newton I (2008) The migration ecology of birds. Academic Press, London

Parmesan C (2006) Ecological and evolutionary responses to recent climate change. Annu Rev Ecol Syst 37:637-669
Parmesan C, Yohe G (2003) A globally coherent fingerprint of climate change impacts across natural systems. Nature 421:37-42

Parry ML, Canziani OF, Palutikof JP, van der Linden PJ, Henson CE (2007) Climate change 2007: impacts, adaptation and vulnerability. Contribution of Working Group II to the Fourth Assessment Report of the Intergovernmental Panel on Climate Change [Parry ML, Canziani OF, Palutikof JP, van der Linden PJ, Hanson CE (eds)]. Cambridge University Press, Cambridge

PECBMS (Pan-European Common Bird Monitoring Scheme) (2009) The state of Europe's common birds 2008. CSO/ RSPB, Prague

Pinheiro J, Bates D, DebRoy S, Sarkar D, the R Core team (2008) nlme: linear and nonlinear mixed effects models. $\mathrm{R}$ package version 3.1-89, R Foundation for Statistical Computing, Vienna

Pulido F, Berthold P (2010) Current selection for lower migration activity will drive the evolution of residency in a migratory bird population. Proc Natl Acad Sci USA 107: 7341-7346

Pulido F, Widmer M (2005) Are long distance migrants constrained in their evolutionary response to climate change? Ann NY Acad Sci 1046:228-241

R Development Core Team (2008) R: a language and environment for statistical computing. R Foundation for Statistical Computing, Vienna

Robinson RA, Crick HQP, Learmonth JA, Maclean IMD and others (2009) Travelling through a warming world: climate change and migratory species. Endang Species Res 7:87-99

Rubolini D, Spina F, Saino N (2005) Correlates of timing of spring migration in birds: a comparative study of transSaharan migrants. Biol J Linn Soc 85:199-210

> Rubolini D, Møller AP, Rainio K, Lehikoinen E (2007) Intraspecific consistency and geographic variability in temporal trends of spring migration phenology among European bird species. Clim Res 35:135-146

Saino N, Szép T, Ambrosini R, Romano M, Møller A (2004) Ecological conditions during winter affect sexual selection and breeding in a migratory bird. Proc R Soc Lond B 271:681-686

> Saino N, Ambrosini R, Rubolini D, von Hardenberg J and others (2011) Climate warming, ecological mismatch at arrival and population decline in migratory birds. Proc $\mathrm{R}$ Soc Lond B 278:835-842

Siriwardena GM, Wernham CV (2002) Synthesis of the migration patterns of British \& Irish birds. In: Wernham. C V, Toms MP, Marchant JH, Clark JA, Siriwardena GM, Baillie SR (eds) The migration atlas: movements of the birds of Britain and Ireland. T. \& A. D. Poyser, London, p 70-102

Speek G, Clark JA, Rohde Z, Wassenaar RD, Van Noordwijk AJ (2001) The EURING Exchange-Code 2000. Vogeltrekstation Arnhem, Heteren

Spina F (1998) The EURING swallow project: a large-scale approach to the study and conservation of a long-distance migrant. In: Leshem J, Lachman E, Berthold P (eds) Migrating birds know no boundaries. Proceedings of the international seminar 1997. Torgos 28:151-162

> Stutchbury BJM, Tarof SA, Done T, Gow E and others (2009) Tracking long-distance songbird migration by using geolocators. Science 323:896

Szép T, Møller AP, Piper S, Nuttall R, Szabo ZD, Pap PL (2006) Searching for potential wintering and migration 
areas of a Danish barn swallow population in South Africa by correlating NDVI with survival estimates. J Ornithol 147:245-253

Thomas CD, Lennon JJ (1999) Birds extend their ranges northwards. Nature 399:213

Tucker GM, Heath MF (1994) Birds in Europe: their conservation status. Birdlife International, Cambridge

Valiela I, Bower JL (2003) Shift in winter distribution in birds: effects of global warming and local habitat change. Ambio 32:476-480

Végvári Z, Bokonv V, Barta Z, Kovacs G (2010) Life history predicts advancement of avian spring migration in response to climate change. Glob Change Biol 16:1-11

- Visser ME, Perdeck AC, van Balen JH, Both C (2009) Climate change leads to decreasing bird migration distances. Glob Change Biol 15:1859-1865

Wernham CV, Siriwardena GM (2002) Analysis and interpretation of the ring-recovery data. In: Wernham CV, Toms MP, Marchant JH, Clark JA, Siriwardena GM, Baillie SR (eds) The migration atlas: movements of the birds of Britain and Ireland. T. \& A. D. Poyser, London, p 44-69

Appendix. Further details on statistical analyses

\section{Analysis of migratory connectivity}

The degree of migratory connectivity shown by barn swallows was assessed by a Mantel test on great-circle (orthodromic; Imboden \& Imboden 1972) distance matrices between individuals calculated separately for the breeding and the wintering grounds (Ambrosini et al. 2009). Because analyses showed significant connectivity (see 'Results'), we identified the main clusters in which the population could be divided with the pam procedure in the cluster library (Maechler et al. 2005) in R 2.8.1 (R Development Core Team 2008). The pam procedure is a clustering algorithm that partitions observations in a number of clusters identified a priori. As a measure of the goodness of the classification of data into a given number of clusters, the procedure returns the overall average silhouette width (oasw), a dimensionless coefficient ranging from -1 to 1 . Increasing oasw values indicate better classification of data (Rousseeuw 1987), and the best number of clusters in which data can be partitioned can be chosen as the number that maximizes the oasw. This analysis resulted in the classification of barn swallows into 2 clusters (see also Ambrosini et al. 2009), one including 495 barn swallows wintering between $15.20^{\circ} \mathrm{N}$ and $12.55^{\circ} \mathrm{S}$ (Cluster North) and the other including 547 individuals wintering between $8.83^{\circ}$ and $34.80^{\circ} \mathrm{S}$ (Cluster South) (Figs 1B, 2). According to Ambrosini et al. (2009), the clusters so identified represent groups of swallows that both breed and winter close together, as cluster classification is based on the reciprocal position of individuals both in the breeding and the wintering quarters.

\section{Details on regression analyses}

Wintering latitudes and longitudes were regressed on year, cluster, their interaction and the linear and squared terms of date of recovery in the wintering grounds to statistically account for the possibility that recoveries referred to individuals still or already on migration. A Gaussian error distribution was assumed, and normality of residuals and presence of highleverage points was checked by inspection of residuals and leverage vs. fitted values plots and QQ-plots. In addition, generalized least squares (GLS) models accounting for heteroscedasticity between clusters and along covariates were fitted to data and their AIC values were compared with those from the linear regression (LR) models. In the models of variation in wintering longitude, GLS fitted the data better than LR models, and heteroscedasticity was therefore accounted for in the final models. Conversely, models of wintering latitude did not show any deviation from homoscedasticity of residuals, and were therefore fitted by LR models. Non-significant predictors were removed from final models.

\section{LITERATURE CITED}

Ambrosini R, Møller AP, Saino N (2009) A quantitative measure of migratory connectivity. J Theor Biol 257: 203-211

Imboden C, Imboden D (1972) Formel für Orthodrome und Loxodrome bei der Berechnung von Richtung und Distanz zwischen Beringungs- und Wiederfundort. Vogelwarte 26:336-346

Maechler M, Rousseeuw P, Struif A, Hubert M (2005) Cluster analysis basics and extensions: cluster $\mathrm{R}$ package version 1.11.11. www.cran.r-project.org/web/packages/ cluster/ (Accessed 29 September 2008)

R Development Core Team (2008) R: a language and environment for statistical computing. R Foundation for Statistical Computing, Vienna

Rousseeuw PJ (1987) Silhouettes: a graphical aid to the interpretation and validation of cluster analysis. J Comput Appl Math 20:53-65 